\title{
ENTREVISTA| Epigrafe
}

Entrevista com

\section{LUIZ FELIPE DE ALENCASTRO}

Realizada em São Paulo, em 27 de Agosto de 2013

Em sua mais recente passagem pelo Brasil, o historiador Luiz Felipe de Alencastro, autor do clássico O Trato dos Viventes e co-autor de diversas outras obras de extrema relevância para a historiografia, cedeu uma entrevista à Revista Epígrafe, após ter ministrado a palestra "A Exceção cultural francesa", no Departamento de História da Universidade de São Paulo.

Durante uma conversa descontraída, o historiador - que atualmente é professor na Universidade de Paris IV - Sorbonne, diretor do Centre d'Etudes du Brésil et de I'Atlantique Sud e professor convidado da EESP da FGV - falou sobre sua vivência de graduação, sobre as mudanças ocorridas no ambiente estudantil desde a época em que era um graduando, e sobre temas relacionados à função social do Intelectual na contemporaneidade - além de ter revelado ser um torcedor assíduo do clube Paris Saint-Germain, do Corinthians e do Botafogo.

\section{_ Motivaçõos para ingressar num curso de Ciências Humanas}

Eu estudei no colégio jesuíta de Florianópolis, o Colégio Catarinense, e tive um professor, o padre João Alfredo Rohr, arqueólogo e pioneiro no estudo paleoameríndio sobre os sambaquís, que me influenciou bastante. Também tiveram muito impacto sobre mim aquela paisagem, aquela presença humana. O padre Rohr foi um grande defensor da preservação dos sambaquís, que eram destruídos e utilizados como reserva de cal na época. Depois desse período, meus pais se mudaram para Brasília e eu entrei na UNB num período de grande politização - um mês antes do Golpe. Fui para a França porque a repressão começou a cercar os estudantes e os professores da UNB. Graças a alguns deles, eu consegui uma bolsa de estudos francesa e fui fazer Ciências 


\section{ENTREVISTA| Epigrafe}

LUIZ FELIPE DE ALENCASTRO

Políticas e História em Aix-en-Provence em 1966. Fiquei vinte anos na França. Estive em Paris em 1970, onde fiz doutorado e ensinei na Universidade de Vincennes, e voltei ao Brasil em 1986.

$\mathrm{Na}$ França, houve uma mudança total na vida, porque eu tinha vinte anos. Logo ao chegar, ingressei na faculdade e fiz amizades. Digo a vocês: amizade se faz na graduação - na pós-graduação, as pessoas já estão com a cabeça feita, não têm a mesma convivência de sala de aula. É na graduação que se vai à aula todo dia, que se convive com as pessoas que irão te acompanhar pelo resto da vida.

\section{_ A graduação nas décadas de 1960 e 1970 e o ambiente estudantil contemporâneo}

O ambiente era bem mais politizado, mas esta é também uma questão cíclica: quando se acha que está tudo calmo, recomeçam manifestações. Em Paris, há 3 por dia e um terço delas não tem nada a ver com a França. Há também outra coisa: o ambiente estudantil e social na França é muito cosmopolita. Fiz bons amigos africanos em Aix-en-Provence, gente boa, sofrida, militantes sinceros, mas também havia diletantes simpáticos. Comecei a me interessar na África mais de perto nesta época. Houve um longo período de grandes agitações políticas e sociais a partir de maio 1968, que terminou com a eleição do François Mitterrand em maio 1981. Com a esquerda no poder, houve menos manifestações nas ruas. Mas há sempre mobilizações anti-racistas importantes.

Nos anos 1970 ocorreram também grandes debates em torno da liberação do aborto na França e também pelo fim da pena de morte. A partir daí, houve manifestações mais fragmentadas, com alguns momentos de mobilização mais intensa em torno de questões sindicais, educacionais e culturais. Agora, por exemplo, ocorreram grandes manifestações contra e a favor do casamento gay em Paris e nas grandes cidades francesas.

Os Cafés parisienses sempre foram um grande espaço de produção intelectual. Ficar horas a fio lendo e escrevendo nestes lugares, sem perturbações, fazia parte da 


\section{ENTREVISTA| Epigrafe}

LUIZ FELIPE DE ALENCASTRO

tradição estudantil e intelectual francesa. Sartre escreveu uma parte de Sursis e O Ser e o Nada no Café de Flore, em Saint-Germain-des-Près. Milhares de estudantes secundaristas e universitários fazem suas lições de casa nesses cafés.

Há 10-15 anos atrás, quando meu filho estava saindo do secundário e entrando na Universidade, ainda era muito assim. Os estudantes passavam horas num café preparando as aulas, discutindo e namorando. Hoje mudou um pouco. Pelo menos perto da Sorbonne os Cafés ficaram mais "chiques", atendendo mais os turistas, ou

mesmo fecharam as portas, transformando-se em fast-foods. A Starbucks, por exemplo, está de olho ali, subindo aos poucos por alguns pontosque ela já comprou no boulevard Saint Michel e no boulevard Saint Germain, pelejando para abrir uma franquia na praça da Sorbonne. O Café com um terraço simpático da Praça Saint Sulpice é assediadíssimo pelas grandes marcas de moda para passar o ponto.

\section{_ A função social do Intelectual e do Acadêmico}

Na França, há uma tradição - que também havia no Brasil anteriormente, mas que agora está mais arrefecida - em que os intelectuais intervêm em todo tipo de debate. Alguns acham esta tradição um tanto quanto ultrapassada porque há mais especialização e só os economistas podem escrever sobre a economia, os juristas sobre a justiça e assim em diante. Mas esse tipo de intervenção possui grande relevância: os jornais franceses, inclusive, abrem seções para que diversas discussões sejam feitas, e não é necessário ser um especialista para dar palpites sobre os assuntos - mesmo naqueles que não forem da sua área. Ou seja, a imprensa ainda é muito aberta aos debates. Eu tenho uma coluna no UOLNews onde escrevo sobre política internacional. Também acho que manter um blog é algo muito bom, tenho um chamado 'Sequências Parisienses', que está um pouco desatualizado. Mas ainda costumo escrever quando surge algum debate de relevância.

Por exemplo, há uns dias postei no meu blog 'Sequências Parisienses', um texto sobre a França. Há um concurso francês muito específico e disputado, para ser 


\section{ENTREVISTA| Epigrafe}

LUIZ FELIPE DE ALENCASTRO

professor permanente do ensino secundário, a "agrégation". Cada disciplina tem a sua “agrégation". Embora não esteja escrito nos editais dos concursos para o ensino universitário, a maioria das universidades exige que os candidatos a assistentes tenham, além do doutorado, a "agrégation". O tema escolhido vale por dois anos, é ensinado para os candidatos ao concurso e também desencadeia um processo editorial porque os editores preparam livros e coletâneas específicas para os candidatos à "agrégation".

Neste ano, em História Contemporânea, o tema é a "As sociedades coloniais 1850-1950". Em História Moderna, o tema é "A Península Ibérica e o mundo dos anos 1470 até os anos 1640". Serge Gruzinski e eu achamos que a periodização escolhida, excluindo a expulsão dos holandeses do Brasil (1654) e os eventos ocorridos até o reconhecimento da nova dinastia dos Bragança pela Espanha e pelo Papa (1668), é muito mais focada no mundo espanhol do que sobre o império português. Aí redigimos um texto que foi publicado no blog sobre a América Latina no Le Monde. Foi este texto que publiquei no meu blog.

\section{_ A questão da especialização e o pouco interesse na História global}

Eu estava falando do (Serge) Gruzinski, que é um dos raros historiadores que faz esses estudos globais na França. As pessoas se especializam apenas em uma área, e é muito difícil ver alguém que se proponha a fazer estudos com uma perspectiva mais ampla, ainda que os Arquivos online tenham muito mais documentação e bibliografia acessível. Algo que facilita o acesso à informação - e consequentemente, à formulação de pesquisas que possuam perspectivas mais amplas. No Brasil, por exemplo, estuda-se pouco a Ásia portuguesa. A China é o maior parcerio comercial do Brasil e creio que não há no país nenhum grande especialista de história chinesa. Posso estar enganado, mas pelo que sei, nem a USP, nem nenhuma outra universidade brasileira tem algum professor que seja especialista sobre os assuntos chineses e seja fluente em mandarim. Porque se for para ser especialista da China a partir da informação da imprensa 


\section{ENTREVISTA| Epigrafe}

LUIZ FELIPE DE ALENCASTRO

européia e americana aí é mole. Fiz uma indagação informal no Itamaraty e soube que na hierarquia mais alta, embaixadores e gente do topo, há menos de meia dúzia de diplomatas que sabem o mandarim.

Além disso, existe ainda a questão da micro-história. Acho certo exagero pensar que a vida de um indivíduo possa conter o "mundo inteiro", me parece algo meio descontextualizado. Além disso, acho que opor micro-história à macro-história não faz sentido: muitos historiadores sabem incluir a primeira nas narrativas mais gerais da segunda. É o caso de Serge Gruzinski, por exemplo. Enfim, há outro assunto que me envolve diretamente. Acho a divisão estrita entre "africanistas" e "especialistas" uma roubada. As universidades brasileiras deviam formar especialistas do Atlântico Sul, um espaço que tem muito mais coerência e continuidade históricas do que a as generalidades que são enfiadas no tema "América Latina".

Mas também é necessário ressaltar que a demanda por teses, nos dias de hoje, é muito mais severa: na minha época, ficava-se anos trabalhando em uma tese, e não havia essa pressão tão grande, pelo menos para muitos de nós. A minha tese, por exemplo, levou mais de dez anos para ser concluída; o Serge Gruzinski também levou um tempão. Hoje, como eu disse, com a Reforma de Bolonha, deve-se fazer uma tese em três, quatro ou cinco anos. O modelo das Ciências Exatas influenciou a organização das Ciências Humanas na França. Isso também ocorre aqui no Brasil. Mas nas Ciências Humanas, em História em particular, o ritmo é outro, mais demorado, mais longo na confrontação das fontes e no domínio da narrativa.

Por isso, os pós-doutorados tornam-se cada vez mais frequentes. O doutorado, apenas, já não basta - é necessário logo engatar uma pesquisa de pós-doc, uma vez que o período de doutoramento é muito curto! (risos).

\section{_ Um tema de relevância no exercício da docência na França}

Eu ensino uma disciplina na Sorbonne, criada por Pierre Chaunu, que aborda a questão dos europeus fora da Europa. Por que fora? Porque em alguns lugares a 


\section{ENTREVISTA| Epigrafe}

LUIZ FELIPE DE ALENCASTRO

presença européia redundou em colonização, noutros lugares, como na Ásia, em particular na China e no Japão, isso só ocorreu mais tarde, no contexto diferente da segunda expansão européia (1850-1950). Costumo enfocar a historiografia portuguesa ao ministrar essa disciplina, que foge um pouco do esquemão francês ou britânico sobre a África e Ásia. Muitos alunos gostam, justamente por não possuírem qualquer contato com a historiografia portuguesa ou lusófona. É certo também que certos estudantes talvez não teriam chances de ter contato com determinados temas se a disciplina não permitisse a adoção desse viés metodológico.

Em Abu Dhabi, onde há um campus da Sorbonne, ministrei essa disciplina por três anos seguidos. Lá, havia um interesse muito grande, sobretudo porque a presença inglesa se sobrepôs ao passado luso-oriental no Golfo Pérsico. Ali restam somente algumas fortalezas portuguesas do século 16, como o forte Jalali (que se chamava São João) mais bonitas que as casernas inglesas do século 19. Esse passado interessa os estudantes dos emirados e pode discutir com eles sobre isso.

\section{_ Questões conflituosas na grade brasileira do curso de História}

$\mathrm{Na}$ graduação brasileira, faltam abordagens como esta que mencionei existir na França. Essa tradição lacunar, no Brasil, vem desde os tempos do Caio Prado, do Roberto Simonsen, e inclusive do Celso Furtado - que foi meu mestre. Havia esse esquema, fixado pelo economista francês Leroy-Beaulieu, que define dois tipos de colônias: de povoamento e de exploração - vocês todos, estudantes, viram isso na graduação. Porém, Oliveira Martins, o grande historiador português do século 19, completou a conceitualização de Leroy-Beaulieu, incluindo as feitorias. Macau, Hong-Kong, Malaca, Singapura, foram colônias de povoamento ou de exploração? Nem uma coisa, nem outra! Os portugueses ficaram em Macau de 1557 até 1999, e não foram sequer um quilômetro para frente - e nem pretendiam ir, estavam ali apenas para fazer comércio, no esquema de offshore, algo essencial para o sistema capitalista até os dias de hoje. Acontece que as colônias foram extintas, mas a ideia de praças offshore, não. $E$ 


\section{ENTREVISTA| Epigrafe}

LUIZ FELIPE DE ALENCASTRO

o que é uma praça offshore? Ora, é uma feitoria. O que havia no Brasil, no início, era uma colonização de fato? Não, havia feitorias! O pulo do gato, a passagem da fase de feitorias para a etapa da colônia ou Colônia, como se costuma escrever no Brasil, só pode ser explicada se a África, e em particular Angola, for incluída na reflexão e na narrativa histórica.

Então, algo que a tradição brasileira não explica, e que deveria ser trabalhado, é justamente essa a questão da diferenciação entre colonização e comércio, que eu havia mencionado anteriormente.

\section{_ Concepções quanto à relação entre graduandos e docentes}

Fiz graduação em Aix-en-Provence, que era uma pequena cidade universitária, era tudo muito próximo e mais fácil do que em Paris. Eu fiz o diploma de Ciências Políticas e também História, porque ali havia o melhor curso de história da França na época.

Em 1970, mudei para Paris e fui fazer o doutorado em História com o Frédéric Mauro na Universidade de Nanterre. Havia ainda o rescaldo de maio 1968 e os exilados brasileiros chegavam em Paris em maior número. A relação lá com os alunos é mais formal. O professor catedrático faz cursos mais gerais para bastante alunos. Já tive salas com perto de 200 estudantes. Depois os assistentes dão mais duas horas de aulas para grupos de 30/40 desses estudantes. Os estudantes tem o hábito de anotar as aulas e é necessário falar encadeado, pois os alunos estão tomando nota da sua fala. Dei aulas em várias universidades francesas, na Unicamp, na University of Massachusetts, na Universidade de Salamanca em menor escala, e agora na Escola de Economia de São Paulo da FGV onde serei professor efetivo a partir de julho, quando me mudar para São Paulo. Acho os estudantes franceses mais bem preparados. Eles têm um ensino secundário público e laico que é de muito bom nível, comparado com o ensino secundário brasileiro, espanhol e até com o americano. Aos 17 anos eles têm um curso de Filosofia o ano inteiro e aprendem, ao longo do secundário, a redigir bem, 


\section{ENTREVISTA| Epigrafe}

LUIZ FELIPE DE ALENCASTRO

elaborar uma dissertação em torno de temas sintéticos e complexos. Isso dá uma grande ajuda quando eles entram nas Universidades.

\section{_ O gosto pelo Futebol}

Eu torço pelo Paris Saint-Germain, que é um time que não tem solução (risos).

É um time de uma grande capital européia, com um belo estádio, muito dinheiro, uma grande torcida, e não ganha nada nunca: um caso único na história do futebol! Em São Paulo sou corinthiano. Mas, de coração, sou Botafogo. Nos anos 1950, em Santa Catarina, quando eu era criança e adolescente, o campeonato do Rio era o verdadeiro campeonato nacional. 